\title{
A EXTENSÃO UNIVERSITÁRIA E A PRÁXIS NA FORMAÇÃO INICIAL E CONTINUADA DODISCENTE
}

\author{
Ivanalda Dantas Nóbrega Di Lorenzo ${ }^{1}$ \\ Jefferson Santos Fernandes ${ }^{2}$ \\ Kaiame Leite Araújo ${ }^{3}$
}

\begin{abstract}
RESUMO
Apresentamos reflexões sobre a extensão universitária como importante mecanismo de aprendizagem na formação dodiscente, no Ensino Superior, por ocasião da formação inicial e, na Educação Básica, por ocasião da formação continuada docente, de professores de escolas do campo, no município de Aparecida, Sertão Paraibano. Enaltecemos como a universidade se faz presente e importante na ação de extensão e os resultados da interatividade para os educandos envolvidos, bolsista e voluntários, assim como com os professores da Educação Básica, especialmente por compreendermos as profundas transformações no ensino e, na educação brasileira somadas ao advento das tecnologias da informação e da comunicação. A metodologia envolve pesquisa bibliográfica, de campo e documental, com entrevista semiestruturada, questionários, caderneta de campo, levantamento fotográfico e gravação de eventos em áudio e vídeo. A compreensão da temática abordada envolve autores que refletem sobre extensão, a interdisciplinaridade, formação docente e a Educação do Campo. Além da introdução e considerações, este artigo apresenta dois subitens, referentes à apresentação do Projeto interdisciplinar na formação inicial e continuada do discente; e, a extensão universitária, a práxis e a Política da Educação do Campo.
\end{abstract}

Palavras-chave: Extensão Universitária - Formação Dodiscente - Educação do Campo.

\section{THE UNIVERSITY EXTENSION AND PRACTICE IN INITIAL AND CONTINUED DODISCENT TRAINING}

\begin{abstract}
Here reflection on the university extension as an important learning mechanism in dodiscente training, higher education, during the initial training and in Basic Education, at the teacher continuing education in the field of school teachers in the city of Aparecida, in Paraiba states. We laud as the university is present and important to the extent of action and interactivity results for the students involved, scholarship and volunteers, as well as teachers of basic education, especially for understanding the profound changes in education and in Brazilian education combined the advent of information and communication technologies. The methodology involves bibliographic research, field and documentary with semi-structured interviews, questionnaires, field notebook, photographic survey and event recording audio and video. Understanding the topic addressed involves authors who reflect on extension, interdisciplinarity, teacher training and the Rural Education. Besides the introduction and considerations, this article presents two sub-items, regarding the presentation of the interdisciplinary project in initial and continuing training to student-teach; and the university extension, praxis and Rural Education Policy.
\end{abstract}

Keywords: University Extension - Student Formation - Rural Education. INTRODUÇÃO

\footnotetext{
${ }^{1}$ Professora Adjunta da Universidade Federal de Campina Grande/ CFP/UFCG. E-mail: ivanaldadantas@gmail.com

${ }^{2}$ Graduando da Universidade Federal de Campina Grande. E-mail: jefferson.geo.fernandes@gmail.com

${ }^{3}$ Graduando da Universidade Federal de Campina Grande. E-mail: kayamearaujp@ hotmail.com
} 
A sociedade atual perpassa transformações e crises, no ensino e na educação, as quais expressam suas marcas na formação e atuação profissional, cujos resultados especialmente, na educação se expressam nos índices deficitários obtidos frente aos almejados pelos Organismos Multilaterais financiadores do desenvolvimento, em escala mundial, como a Organização Internacional do Trabalho (OIT), o Banco Mundial (BM) e o Fundo Monetário Internacional (FMI).

Considerando essa assertiva apresentamos neste trabalho reflexões sobre um projeto de extensão, vigente de maio a dezembro de 2016, com atuação no município de Aparecida, Sertão Paraibano, na Escola pública Lili Queiroga, do Assentamento rural Acauã. O referido Projeto insere-se no Probex 2016, no âmbito do Centro de Formação de Professores (CFP), da Universidade Federal de Campina Grande (UFCG) e objetiva realizar a atividade de extensão universitária no processo de formação continuada de Educadores do Campo e, simultaneamente, a formação inicial de Graduandos do curso de Licenciatura em Geografia, do Centro de Formação de Professores (CFP), UFCG.

A pesquisa inclui a participação de 10 educandos, sendo um bolsista e 09 voluntários e, 05 educadores, a partir dos quais procuramos compreender se ocorre a educação interdisciplinar, seguindo os princípios da Política Pública da Educação do Campo. Os parceiros são a Associação de Agricultores do Assentamento Acauã (AAAA), Escola Municipal Lili Queiroga e Secretaria de Educação do município de Aparecida-PB. O recorte temporal de pesquisa para este trabalho se dá entre os meses de maio a setembro de 2016.

Além da introdução e considerações, este artigo apresenta dois subitens, referentes à apresentação do Projeto interdisciplinar na formação inicial e continuada dodiscente; e, a extensão universitária, a práxis e a Política da Educação do Campo.

Desenvolvemos uma ação investigativa e uma intervenção educativa, tendo como base uma visão crítica da realidade social com a utilização de aplicação de questionário; entrevistas com as professoras da escola; levantamento bibliográfico, revisão teórica sobre a temática Educação do Campo, movimentos sociais, formação e ação docente, e interdisciplinaridade buscando identificar, relacionar, analisar o tema, 
avaliar, propor e realizar ações junto aos professores da Escola, com vistas à melhoria da ação docente e da educação.

\section{Conhecendo o Projeto de Extensão na Perspectiva da Interdisciplinaridade e da Formação Inicial e Continuada Dodiscente}

A propositura do projeto que envolve pesquisa e extensão está em realização e se fundamenta numa perspectiva qualitativa de pesquisa-ação, através de oficinas pedagógicas, as quais pretendem desenvolver atividades de formação continuada com professores da escola do campo do Assentamento Acauã, município de Aparecida, no Estado da Paraíba. Inclui o desenvolvimento de dezesseis oficinas, 01 Encontro e 01 Mostra Cultural, e a formação inclui as temáticas, Educação do Campo e Ensino Interdisciplinar, com a propositura central de discuti-las teoricamente, associadas ao debate, construção e utilização de metodologias, linguagens e, recursos didáticos no ensino interdisciplinar, capazes de tornar atrativa e inteligível a compreensão do espaço geográfico, pelos educadores em formação e pelos educandos, a partir das práticas dos educadores em formação em suas salas de aula, durante a vigência do projeto, como um reflexo constante da práxis docente e, do repensar teoria e prática seguindo a concepção da pedagogia da alternância.

Apresentamos como objetivo realizar a formação continuada de educadores/as, com vistas à reorganização e execução do Projeto Político Pedagógico, da Escola Municipal de Ensino Fundamental Lili Queiroga, tomando como ponto de partida a atividade de extensão acadêmica fortalecendo a formação docente dos estudantes monitores (bolsistas e voluntários). Os objetivos específicos são: a) Promover encontros de formação continuada para os professores; b) Oportunizar estudos sistemáticos sobre a Educação do Campo e o Ensino Interdisciplinar; c) Construir materiais didático-pedagógicos; d) Realizar um mostra cultural e 01 encontro.

Como opção metodológica para a ação extensiva, o diálogo se torna um elemento essencial, especialmente porque a concepção de Educação do Campo defendida pelos movimentos sociais se inspira em Paulo Freire, educador que defende o diálogo como instrumento pedagógico fundamental para se efetivar uma educação para 
a liberdade e, para a autonomia, como objetivos que devem contemplar a formação humana.

O caráter dialógico da formação inicial e continuada docentes e da atuação docente compreende-se a partir da concepção de que, não é possível ensinar-aprendendo sem a disposição para o diálogo, o "diálogo dodiscente" (FREIRE, 1995). Segundo o autor (ibidem) o diálogo pressupõe a interação entre diferentes sujeitos que ensinamaprendendo e aprendem-ensinando através dele, o qual representa a condição para a ação pedagógica, ação esta que só se processa no seu próprio exercício dialógico, carregado de intencionalidade(s) pedagógica(s), que se organiza(m) a partir do compromisso de transformar a realidade em que o sujeito está inserido.

Partimos da história local do Assentamento Acauã, portanto, consideramos o histórico de enfrentamentos e despejos realizados pela justiça junto aos agricultores acampados na Fazenda Acauã, somado ao histórico das lutas pela permanência na terra conquistada, desapropriada pelo Instituto Nacional de Colonização e Reforma Agrária (INCRA) em 14 de outubro de 1996, com um total de 2.825 hectares de terra.

O Assentamento Acauã se tornou o primeiro assentamento do Alto Sertão da Paraíba, a partir da desapropriação de terras privadas, ditas improdutivas viáveis, ou seja, capazes de produzir, mas em situação de descumprimento da função social da terra. O conhecimento dessa realidade necessita ser abordado nos espaços escolares como vistas à promoção da formação de professores, assim como na formação inicial, o que pode ser realizado a partir da extensão universitária, através da interatividade na relação universidade-escola, entendendo que a partir do próprio ordenamento legal que rege a educação e aos cursos de Licenciaturas, está implícita o tratamento da educação contextualizada.

Daí surge uma das maiores motivações para a realização do Projeto de educação continuada e formação de Educadores na Escola Lili Queiroga, no Assentamento Acauã, uma vez que a problemática mencionada merece um destaque e olhar interdisciplinares, tendo em vista abranger aspectos multidimensionais, especialmente se considerarmos que a maioria dos conflitos de terra do Sertão Paraibano, desenvolvese em torno da área seca de um açude público, ou seja, em função de dois recursos naturais fundamentais à sobrevivência humana no Semiárido: a água e a terra (MOREIRA; TARGINO, 1997, p. 91). Além disso, há outros aspectos a ser considerado na educação escolar como o associativismo em área de assentamento rural, a história de RPI Revista de Pesquisa Interdisciplinar, Cajazeiras, v. 1, Ed. Especial, 553 - 563, set/dez. de 2016. 
luta e espacialização dessas lutas na terra conquistada, as religiosidades locais, educação contextualizada e as novas metodologias no ensino, dentre outros.

Pensando a diversidade que caracteriza os seres humanos, e nestes, os sujeitos camponeses e sujeitos da escola do campo, achamos importante destacar que apesar das recentes iniciativas de educação (PRONERA, PROCAMPO, PROJOVEM CAMPO) para os povos que vivem no campo brasileiro, ainda persistem os indicadores de iniqüidade que denunciam a injustiça que recai sobre as populações que habitam no campo.

Ressaltam-se os seguintes indicadores apontados por estudo recente (MOLINA et al, 2009, p. 5): a) A taxa de analfabetismo da população de 15 anos ou mais é de 23,3\% na área rural, é superior à da zona urbana, que é de 7,6\%. b) A escolaridade média da população de 15 anos ou mais, que vive na zona rural é de 4,5 anos, e no meio urbano, na mesma faixa etária, encontra-se em 7,8 anos. O nível de instrução da população adulta jovem, na faixa de 25 a 34 anos, confirma o quadro de desigualdade. Enquanto para a população urbana nesta faixa etária, 52,5\% tem instrução completa de nível médio ou superior, no meio rural essa condição só existe para 17\% da população, segundo os dados da Pnad 2007.

O campo, em geral apresenta dificuldades em sua estrutura no tocante a um conjunto de problemas e dificuldades: a insuficiência e a precariedade das instalações físicas da maioria das escolas; as dificuldades de acesso dos professores e alunos por falta de um sistema adequado de transporte escolar; a falta de professores habilitados e efetivados, o que provoca constante rotatividade; currículo escolar que privilegia uma visão urbana de educação e desenvolvimento; quase sempre, a ausência no local da escola de assistência pedagógica e supervisão escolar; o predomínio de classes multisseriadas com educação de baixa qualidade; a falta de atualização das propostas pedagógicas das escolas rurais; baixo desempenho escolar dos alunos; elevadas taxas de distorção idade-série; baixos salários e sobrecarga de trabalho dos professores, quando comparados com os dos que atuam na zona urbana (MEC/INEP, 2007).

Na Escola Lili Queiroga desenvolve-se o sistema Seriado e através de formações contínuas de professores, busca-se minimizar os impactos e a existência desses problemas, já que os alunos são da mesma comunidade, residentes numa agrovila do Assentamento Acauã, onde se situa a escola.

RPI Revista de Pesquisa Interdisciplinar, Cajazeiras, v. 1, Ed. Especial, 553 - 563, set/dez. de 2016. 
Nosso interesse em abordar a formação segundo a interdisciplinaridade implica que entendemo-la como uma condição fundamental do ensino e da pesquisa, na sociedade contemporânea, sendo a prática interdisciplinar considerada oposta a qualquer homogeneização. Portanto, pensamos no Projeto de extensão atividades e ações disciplinares e interdisciplinares com lógicas distintas que visem o equilíbrio entre a análise fragmentada e a síntese simplificadora (JANTSCH \& BIANCHETTI, 2002), desenvolvida por uma coletividade, mas procurando verificar o singular (KLEIN, 1990), em suas distintas multidimensionalidades e manifestações.

Nesse sentido, a interdisciplinaridade e suas relações com a cultura escolar incluem o pensamento de distintas disciplinas, mas vai além disso, conforme afirma Japiassú (1976, p. 75), pois há "a colaboração entre as diversas disciplinas o entre os setores heterogêneos de uma mesma ciência conduz a interações propriamente ditas, isto é, a uma certa reciprocidade nos intercâmbios".

Consideramos as disciplinas escolares e culturas escolares, a percepção de dois movimentos em direções opostas, mas não excludentes: a tradição da organização escolar em disciplinas continua e se fortalece; e a acentuada tendência para simplificálas e até mesmo reduzi-las em áreas. Tal visão nos remete, todavia, apenas a aspectos internos à escola, mais precisamente à organização dos conteúdos de ensino, às metodologias de ensino-aprendizagem, ao horário escolar, dentre outras. São estes, dentre outros aspectos que procuramos desenvolver na análise e execução do Projeto de Formação Continuada aqui mencionado, desenvolvido a partir da extensão universitária.

\section{A Extensão Universitária como Elemento da Práxis Educadora nos Parâmetros da Política da Educação do Campo}

No intuito de atender às demandas societárias em suas múltiplas dimensões foi criada a universidade pública brasileira, onde se produzem conhecimentos e se forma a cidadania dos sujeitos através da educação.

A universidade pública centra-se em três pilares essenciais, os quais sustentam sua lógica primordial de ensino-aprendizagem: ensino, pesquisa e extensão. Considerada como importante mecanismo na formação discente, ela consiste na interatividade entre a universidade e a comunidade do entorno, com a qual mantém ou 
deseja se interrelacionar formando vínculos com a sociedade que recebe assistência ou, com a qual constrói conhecimentos intercomplementares, consubstanciando a práxis social.

A extensão universitária é regida mediante o Plano Nacional de Extensão, construído pelo Fórum de Pró-Reitores de Extensão das Universidades Públicas Brasileiras e, pela Secretaria do Ensino Superior do Ministério da Educação e do Desporto.

Articulando ensino, pesquisa e extensão, a extensão universitária consolida a relação universidade-escola ou universidade-comunidade e, por conseguinte, a sociedade e, através desse vínculo possibilita-se a mitigação da extrema desigualdade social existente entre as populações, em suas distintas espacializações.

Portanto, o modelo de universidade pautado no ensino encontra-se cada vem mais sujeito ao fracasso, considerado por Buarque (2003), uma ameaça, uma vez que o meio técnico-científico-informacional promove mutações através da compressão espaço-tempo encurtando, simultaneamente espaços e tempos, ora aproximando, ora promovendo o distanciamento entre povos, em múltiplas dimensões.

Nesse cenário, cabe a universidade a função de mediar às condições de construção de distintos conhecimentos e saberes pautados nas realidades dos sujeitos, e para tanto, a extensão constitui-se como viés indispensável na formação de educandos, pois promove o desenvolvimento da práxis, a partir da ação dialógica e do domínio da linguagem técnica, com a utilização de tecnologias capazes de produção de conhecimentos e, de interação com a sociedade circundante percebendo-se os saberes e as realidades locais.

Nesse sentido, a universidade adentra o espaço da sociedade (e sendo parte dela), acercando-se dessas realidades e saberes, alguns dos princípios da Política da Educação Campo e, através da extensão atuam junto e com os sujeitos, construindo e fortalecendo vínculos entre esses dois espaços, constituindo a práxis, a partir da ação extensiva pautada numa prática sociopolítica e cultural, cujas trocas de conhecimentos (SILVA, 1997) espera-se que corroborem para o fortalecimento dos valores e das culturas locais evitando, de tal modo, que haja violação destes.

A relação entre subjetividade e objetividade expressa a práxis através da ação e reflexão acerca da realidade sobre a qual, a extensão se debruça e, por conseguinte se 
estabelece o processo de humanização dos sujeitos a partir da educação problematizadora defendida por Freire, como ato de liberdade, emancipação e de conhecimento.

Portanto, esse ato educativo deve permear a noção de quem são os sujeitos, bem como suas realidades, conforme preconiza a Política Pública da Educação do Campo. Esta Política expressa os resultados das lutas que os movimentos sociais vêm empreendendo como resultado das contradições do modo capitalista de organização social, econômica e política, imposto pelos colonizadores portugueses, as quais vêm assumindo diferentes formas de organização, plataformas e estratégias de luta, como reflexo das contradições da luta de classes postas em diferentes conjunturas da formação social brasileira.

Portanto, as lutas camponesas por terra incluem a luta por educação que respeite e reconheça a diversidade em suas múltiplas dimensões, conforme afirma Arruti (2011, p. 64) ao referir-se ao campo como sendo indicado por alguns autores como o lugar do outro, lugar de atraso, com a negação de suas realidades.

No contexto brasileiro das duas últimas décadas do século $\mathrm{XX}$ a partir das lutas sociais são reconhecidos novos direitos e novos sujeitos de direito. Nas lutas são definidas identidades e a identidade camponesa se dá na luta, na conquista de território camponês e para firmar e reafirmar essas identidades as propostas educacionais dos movimentos sociais que defendem uma Educação do Campo. Daí a proposição deste projeto pautado na promoção do Ensino de interdisciplinar contextualizado com as realidades dos sujeitos e de seus lugares de vivências.

A gênese da concepção de Educação do Campo remonta aos movimentos populares da década de 1960, ente outros se destacando os Centros Populares de Cultura (CPC`s) e o Movimento de Educação de Base (MEB), e nas experiências e reflexões dos movimentos nos territórios de luta e de conquista, quando desde a itinerância dos acampamentos no calor da luta o coletivo formado pelas as famílias vão construindo alternativas educacionais para seus filhos como as escolas itinerantes, as escolas família agrícolas, as casas familiares rurais, os coletivos de formação, fundamentadas numa pedagogia da indignação, da libertação, da esperança de inspiração Freireana vão construindo a identidade da educação do campo. Proposições que vão se fortalecer nos 
encontros, seminários e conferencias que vem sendo realizadas desde os anos de $1990^{1}$, culminando na formação de um ordenamento legal da Educação do Campo, conformando o Movimento Por uma Educação do Campo, a exemplo de Pareceres, Resoluções, Decretos e criação de Programas como o Programa Nacional de Educação da Reforma Agrária (PRONERA); Saberes da Terra - Programa Nacional de Educação Integrada com Qualificação Social e Profissional para Agricultores/as Familiares - 2005 e ProJovem Campo - Saberes da Terra - 2007; Procampo - Programa de Apoio à Formação Superior em Licenciatura em Educação do Campo; Programa Nacional de Educação do Campo que deve ser implementado a partir do Decreto $\mathrm{n}^{\circ}$ 7.352/2010; e Pronatec Campo.

Não obstante todas essas definições legais e programas em execução desde 1998, com a criação do PRONERA, as escolas do campo continuam, em sua grande maioria alheias a essa perspectiva de educação e continuam vivenciando precárias condições de funcionamento e encontramos na Escola Lili Queiroga a oportunidade de realizarmos a pesquisa e extensão para simultaneamente construirmos um diálogo e estreitarmos a parceria universidade-comunidade.

\section{Considerações}

Com as atividades de oficinas pedagógicas realizadas entre os envolvidos no Projeto esperamos contribuir para a reorganização do PPP desta Escola, planejamento de ensino, de modo que os conteúdos sejam voltados à realidade imediata e local dos educandos, desenvolvendo atividades que incentivem a inclusão dos princípios da Educação do Campo e do Ensino Interdisciplinar, promovendo a criação e o desenvolvimento de materiais didáticos, incentivo à participação dos alunos; incentivo ao professor quanto uma postura democrática e participativa, incentivo à prática de ação e avaliação contínua e participativa, pautada nas realidades dos sujeitos.

A extensão, além de consolidar a parceria universidade-comunidade, fortalece e valoriza os sujeitos que dela participa elevando as condições de se compreender a cidadania dos sujeitos a partir de seus saberes e de suas realidades com vistas à

\footnotetext{
${ }^{1}$ I Encontro Nacional de Educadores e Educadoras da Reforma Agrária (I ENERA), promovido em julho de 1997, em Brasília, pelo Movimento dos Trabalhadores Rurais Sem Terra (MST) em parceria de algumas instituições.
}

RPI Revista de Pesquisa Interdisciplinar, Cajazeiras, v. 1, Ed. Especial, 553 - 563, set/dez. de 2016. 
transformação, além de condicionar a materialização do princípio constitucional de indissociabilidade entre ensino, pesquisa e extensão.

\section{Referências}

BRASIL. Conselho Nacional de Educação. Parecer CNE/CP 009/2001. Brasília, DF, maio de 2001.

. Conselho Nacional de Educação. Parecer CNE/CP 21/2001.

. Resolução CNE/CP n.01, de 18/02/2002. Brasília, 2002a.

. Resolução CNE/CP n.02, de 19/02/2002. Brasília, 2002 b.

. Ministério da Educação e Desporto. Lei No 9.394/96. Brasília, 1996.

. Resolução n⿳01, de 03 de abril de 2002. Brasília, 2002.

. MDA/INCRA. Pesquisa Sobre a Qualidade de Vida, Produção e Renda dos

Assentamentos da Reforma Agrária. Brasília, 2010. Disponível em: www.incra.gov.br. Acesso em 12/05/2012.

CASTELlAR, Sonia Maria Vanzella. A formação de Professores e o Ensino de Geografia. In: Revista Terra Livre 13. Julho de 1999.

FREIRE, Paulo. Conscientização: Teoria e prática da libertação.3. ed. São Paulo: Moraes, 1995.

JAPIASSU, H. Interdisciplinaridade e Patologia do Saber. RJ: Imago, 1976.

JANTSCH, A. P. \& BIANCHETTI, L. (Orgs.) Interdisciplinaridade: para além da filosofia do sujeito. Petrópolis: Vozes, 2002.

UFCG. Projeto Pedagógico do Curso de Licenciatura em Geografia. UFCG, Cajazeiras: 2008. 